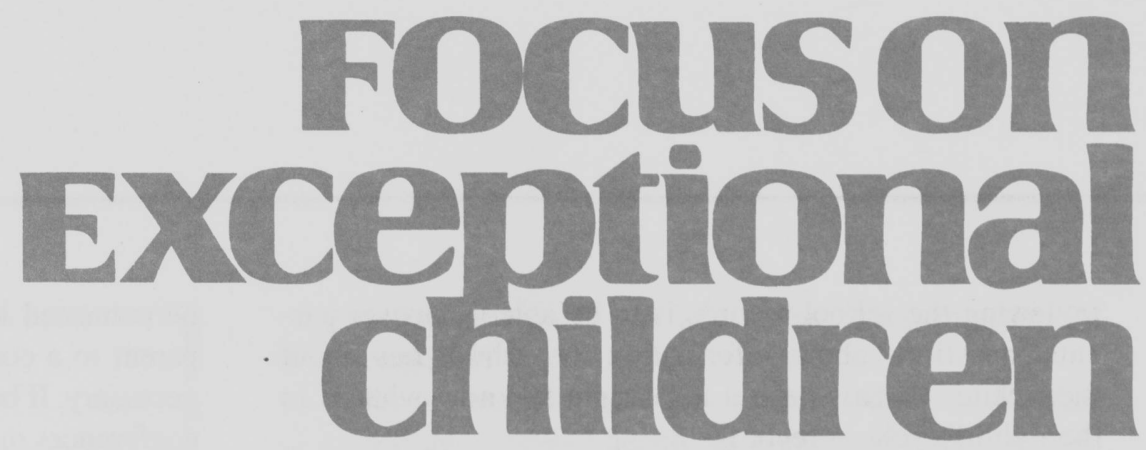

\title{
Parent-Teacher Conferences
}

\author{
Roger L. Kroth and Denzil Edge
}

During the formative years, a child's parents and teachers are the most significant adults in the child's life. Separately and together they provide the care and support, opportunities to learn, and skills the child needs to become a successful, productive adult (Benard, 1991). With the typical child, these significant adults should meet occasionally to exchange information about the child's progress. With children who have disabilities, more frequent meetings are essential for the child's welfare. In fact, federal law mandates parent-professional meetings at specific points related to the child's placement and educational programming.

One of the reasons for the frequently suggested reduction in class size is to give parents and teachers more of a chance to work together. This is especially important with parents of children who have disabilities, to ensure that their children receive the proper individual educational programming. Small-group meetings and individual conferences are more feasible when the teacher is able to relate to 15 sets of parents instead of 30 sets of parents. Frequent interactions allow parents to share information with the teacher, receive information from the teacher, and work with the teacher in preventing and solving problems that involve their children.

Conferences held before school starts in fall or early in the school year can get the child off to the best possible start. Holding conferences early has been demonstrated to result in improved grades and attendance and fewer disciplinary contacts. Holding conferences early gives the teacher and parent alike an opportunity to get acquainted and exchange pertinent information when both are fresh and do not bring existing problems to the exchange.

\section{CUMULATIVE RECORDS}

In preparing for this first conference, the teacher should review the available information about the child and family. Many times, any difficulties the child has had in school can be identified early, and the teacher can provide assistance before the child gets off to a poor start. The records also may contain a number of inconsistencies that can be cleared up in an early conference with the parents. Another good reason for

Roger L. Kroth is professor emeritus at the University of New Mexico. Denzil Edge is president of The Learning House in Louisville, Kentucky. This article was adapted from Communicating With Parents and Families of Exceptional Children, published by Love Publishing Company, 2007. 
reviewing the school records is to be able to answer parents' questions about information the school has about their child. Parents have a legal right to know what is in their child's school records.

A cumulative record folder is available to teachers on children who have been in school somewhere else, too. The four categories of information to which the teacher should pay particular attention pertain to the child's social, academic, intellectual, and physical growth and development.

\section{Social History}

From a careful reading of the records, the teacher may be able to determine some things about the family constellation and dynamics. For instance, the teacher might be able to determine whether the child is living with both parents, if both work outside of the home, and whether the family includes older children. This type of information can help the teacher arrange conferences so the parents can attend and might indicate whether older children are available to babysit and perhaps help tutor their sibling. Depending on the primary language spoken at home, communication may

\section{Focuson
Exceptional
children}

ISSN 0015-511X FOCUS ON EXCEPTIONAL CHILDREN (USPS 203-360) is published monthly except June, July, and August as a service to teachers, special educators, curriculum specialists, administrators, and those concerned with the special education of exceptional children. This publication is annotated and indexed by the ERIC Clearinghouse on Handicapped and Gifted Children for publication in the monthly Current Index to Journals in Education (CIJE) and the quarterly index, Exceptional Children Education Resources (ECER). The full text of Focus on Exceptional Children is also available in the electronic versions of the Education Index. It is also available in microfilm from Serials Acquisitions, National Archive Publishing Company, P.O. Box 998, Ann Arbor, MI 48106-0998. Subscription rates: individual, $\$ 42$ per year; institutions, \$56 per year. Copyright @ C 2007, Love Publishing Company. All rights reserved. Reproduction in whole or part without written permission is prohibited. Printed in the United States of America. Periodical postage is paid at Denver, Colorado. POSTMASTER: Send address changes to:

Love Publishing Company

Executive and Editorial Office P.O. Box 22353

Denver, Colorado 80222

Telephone (303) 221-7333

\section{EDITORIAL BOARD}

Lisa Dieker
University of Central Florida

Paula Maccini University of Maryland

Marleen Pugach

University of Wisconsin-Milwaukee

Carrie E. Watterson Editor
Stanley F. Love

Publisher be enhanced by having a bilingual friend accompany the parent to a conference, or making available a translator if necessary. If both parents work outside the home, arranging conferences may be more difficult and require flexibility on the teacher's part.

The cumulative record may contain some information on the child's social life-any groups the child belongs to, churches attended, and interactions with other children in the past. If the record points out any problems with other youngsters, the teacher may want to gently explore this with the parents at their first meeting. The teacher should be looking for techniques to help the child have some positive early experiences in the new school year, and the parents, in turn, may be able to provide information that will be useful to the teacher.

At this point, the teacher is seeking to understand the child in his or her environment and is looking for areas to discuss further with the parents. The teacher is not trying to draw conclusions as to why the child behaves as he or she does socially but, rather, to determine whether the child's social behavior seems to carry over to different environments. The teacher also is trying to find out how to best conduct the forthcoming conference.

\section{Academic Achievement}

The child's cumulative record includes information such as standardized achievement test scores, report cards, written reports from previous conferences, and samples of the child's work.

The parents probably received this information in the past, but the teacher should not assume that the parents always fully understood or remember all the information they received. Analysis of the data may raise some questions the teacher will want to discuss with the parents. For instance, in preparing for a conference about Susie's growth in reading as measured by the results of achievement tests (see Figure 1), the teacher, Ms. Skinner, noticed that in the first and second grades, Susie was achieving in reading on grade level, but she leveled off in grades 3 and 4. Ms. Skinner may decide to show the chart to the parent(s) and ask for their input. The teacher also may notice a rather large discrepancy between her reading scores and math scores, which could be another point to discuss. Does Susie show any evidence of the same achievement patterns at home?

The teacher may want to ask the parents how they feel about the reporting system that has been used in the past. Parents often do not realize that teachers can give them information about their child's progress in ways other than, or in addition to, the quarterly report card system the school uses. In reviewing Susie's achievement data, Ms. Skinner might think that more frequent reporting to the parents would benefit the family and Susie alike. 


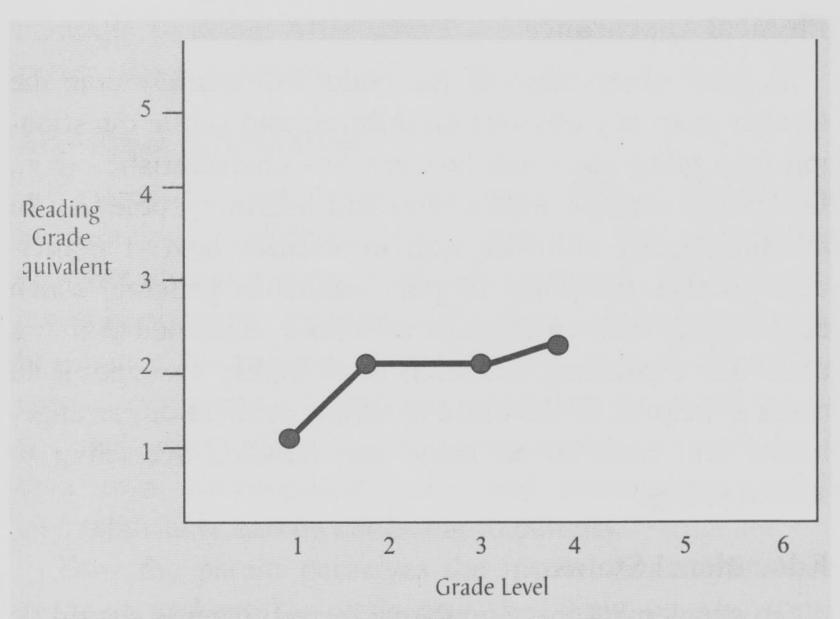

\section{FIGURE 1 Susie's Rate of Reading Achievement}

Susie's parents may have samples of her work at home that would be useful to Ms. Skinner. Children sometimes do school-related tasks - such as writing poetry, keeping track of money they earn from an allowance or a job, drawing pictures, or demonstrating computer skills - that can help the teacher understand the child's skills and interests.

\section{Intellectual Level}

Intelligence quotients (IQs) are numbers laden with emotion. Teachers and parents often attach a great deal of significance to these scores and develop certain expectations that may or may not be warranted. Children with hearing loss, motor dysfunction, emotional disturbance, and those for whom English is not the primary language may have lower scores that do not accurately reflect their intellectual level.

The special educator should be aware of the conditions influencing the various intelligence measures, such as lack of motivation, that might yield a lower reading. The parents may be able to provide additional information about the child that will help the teacher better understand the test scores.

\section{Physical Growth and Development}

The cumulative record may contain information on the child's physical development that will help the teacher answer some of the following questions prior to the child's entering class for the new school year.

- How does the child compare in size to the other children who will be in the same room? Will the chair and desk be the right size for him? Will anything about his disability lead to teasing or hurt feelings? Is the child overweight? If so, will this limit his participation in recess activities? Are any physical accommodations required?

- Does the child have any sensorial defects? Routine testing by school health personnel may have disclosed that she has $20 / 200$ vision. She may show up in class without glasses, perhaps because she simply doesn't like to wear them, or possibly the family has limited financial resources, in which case the teacher might be able to refer the family to an appropriate resource for help. Or a student's hearing test may reveal that she has a mild hearing loss. This should alert the teacher to provide special seating in the classroom.

- How does the child's past attendance record look? Did he miss Mondays most frequently? Attention to these and other questions about the child's attendance at school is often helpful in heading off potential problems in school. Obviously, if a child doesn't attend school regularly, the teacher's job becomes more difficult. Small gains may be lost because of irregular attendance.

In short, the teacher can pick up helpful bits of information from a child's cumulative record, and this information can lead to smoother sailing at the beginning of the year. The first meeting with a parent can give rise to many questions from parent and teacher alike. If the teacher is skillful in asking questions, parents' responses can yield valuable information without the teacher being considered "snoopy." Both the teacher and the parents are interested in the child's welfare, and most parents appreciate that the teacher has taken the time to study the child's records before meeting with them.

\section{THE INITIAL PARENT-TEACHER CONFERENCE}

Some school districts and day-care centers permit and even encourage the teacher to have a conference with the parents before the child is accepted into a special education program. The teacher should prepare for this conference so it will run smoothly and be meaningful to both parties. Many professionals utilize some sort of outline in their initial interviews (Maring \& Magelky, 1990).

Educators, too, should have an outline of the information they would like to obtain in an interview. The outline provided in Figure 2 is concerned with the child's growth and development, particularly as it relates to the child's educational life. Although many of the categories are self-evident, occasionally teachers forget one or another. Hence the importance of having an outline or checklist.

\section{Present Status}

If the teacher has little or no prior knowledge of the child, or there are gaps in the record, the first order of business is 


\section{Child's name}

A. Present status

1. Child's age

2. Sex

3. Grade/class/last year's teacher's name

B. Physical appearance and history

1. General impression the child makes

2. Obvious physical strengths and limitations

3. General mannerisms, appearance, etc.

C. Educational status

1. Present school achievement and samples of work

2. Promotions, accelerations, lack of progress and causes

3. Relations with individual teachers, present and past

4. Books and materials used in the last educational setting

5. Tests, individual or group, and types of measures used

\section{Personal traits}

1. Personality-general statement

2. Attitudes toward home, friends, self, family, other students, school

3. Hobbies, play life, leisure-time activities

4. Educational and vocational goals

5. Likes and dislikes-foods, toys, TV programs, etc.

E. Home and family

1. Individuals in the home

2. Socioeconomic level

3. Relations with home-brothers/sisters, parents, other relatives

4. Regular chores, pets, etc.

5. Cooperation from home

6. Record at social agencies

F. Child's work experience (if applicable)

1. Part-time jobs (summer, after school)

2. Attitude toward work, etc.

G. Additional information

1. Sending school (if different from this one)

2. Outside agencies

3. Private sources: doctor, mental health center, etc. (need release forms)

4. Health information

\section{FIGURE 2 Initial Interview Guide}

usually to find out the name the child likes to be called, age, present status in school, and similar information of a friendly nature. This is a nonthreatening way to begin an interview. Even if the teacher has this information, it's a good idea to verify its accuracy.

\section{Physical Appearance}

A brief observation of the child will quickly clue the teacher as to any obvious disabilities, and subtle questioning may bring out some less obvious characteristics (e.g., fine-motor control, mild vision and hearing problems). In addition, many children with disabilities have a higherthan-average incidence of poor health in general, which could affect their attendance at school. Knowledge that a child has a pending operation or is highly susceptible to colds is helpful. If the child is taking medication, arrangements will have to be made and handled according to school policy.

\section{Educational Status}

To supplement the cumulative record, parents should be invited to bring samples of their child's work that was sent home during the preceding year. And parents can relate some of their child's feelings about, and experiences with, the previous educational setting. From this input, the teacher should be able to ascertain the parents' general attitudes toward school.

\section{Personal Traits}

Exploring the child's hobbies, free-time activities, and likes and dislikes can yield useful information for the first days of school. For example, books with themes of the children's favorite activities may give them an incentive to read. Their preferred activities can be incorporated into assignments. The child's hobbies can be topics for "show and tell" and are helpful in establishing rapport with the child.

\section{Home and Family}

Sometimes the first conference is held in the home. If this is the case, the observant teacher may detect many characteristics of the family's life that will be useful. Pictures, books, magazines, and newspapers reflect the family's socioeconomic status. The home environment also indicates what references and resources (including a computer) the child has available for homework activities.

Determining the predominant language spoken in the home and whether more than one language is used in the home is important, as this will influence home-school programs the teacher may want to set up. Parents may not understand written communications to the home. Daily report cards may not be productive or may require more careful explanation when there are language or cultural differences. What may seem to be a lack of cooperation from the home may actually be a problem in communication.

\section{Work Experience}

With an older child, information to be elicited may include any jobs the child has had and whether the child is 
currently working. After-school jobs may affect the child's performance at school.

\section{Additional Information}

Parents of exceptional children often have been contacted by agencies in addition to school contacts. This information does not always appear in the school records but nevertheless is important to the teacher. For instance, the parents may be involved in conferences held regularly with physical therapists, occupational therapists, psychologists, social workers, and others. These professional specialties each have their own philosophical bases and terminology, which understandably can be confusing to parents.

How the parent perceives the involvement with these agencies and professionals may shed light on why some parents are hesitant to attend parent-teacher conferences. It also may explain parents' desire, or lack of desire, to carry out certain home-school programs. If the various professionals involved with the child unknowingly are making inordinate time and energy demands on parents, the cumulative effect on the parents can be overwhelming. Thus, the teacher can benefit from knowing who is working with the family.

Most parents, in our experience, want to cooperate. They are willing to work within their limits to facilitate their children's growth. The teacher has an obligation to explore the parents' and child's limits by carefully studying the cumulative records and skillfully conducting interviews. By understanding the demands on parents by a child with a disability, the other individuals who live in the house, and the other professionals working with the parents, the teacher can plan more realistically for the child and have more appropriate expectations for parental cooperation.

\section{REGULARLY SCHEDULED CONFERENCES}

Regularly scheduled conferences are the primary basis of parent-teacher interactions. They are identified as a Level 2 need in the mirror model (see chapter 2). State and federal laws require parent-teacher conferences, and they may be written into local school policy. Educators who are skilled in conferencing take advantage of these meetings to provide parents with information and also to elicit from parents information that will further the child's education program.

The outline in Figure 3 may help you prepare for conferences. Having someone videotape you in an actual or roleplayed conference and reviewing the tape also can be helpful.

\section{Preconference}

Taking the four preconference steps listed in Figure 3 will help the conference go smoothly. First, the teacher should prepare some type of notification to be sent home. Although the school may have a form letter, the teacher is responsible for notifying the parents and following up in making the appointment. Appendix A contains tips for parents that can be sent home to help them prepare for this important meeting. Most parents appreciate receiving suggestions.

In preparing for the conference, the teacher should consult the child's cumulative record, as discussed earlier, then develop a plan or agenda. This agenda, of course, should be flexible, with the recognition that it may change after the conference starts.

So much has been written on the effects of the environment on interaction that this may seem like common

\section{PRECONFERENCE}

1. Notify the attendees of the following:

- Purpose

- Place

- Time

- Length of time allotted

2. Prepare by doing the following:

- Review child's folder

- Gather examples of work

- Prepare materials

3. Plan agenda.

4. Arrange environment:

- Comfortable seating

- Eliminate distractions

\section{CONFERENCE}

1. Welcome and establish rapport.

2. State the following to the attendees:

- Purpose

- Time limitations

- Note-taking

- Options for follow-up

3. Encourage the following:

- Information-sharing

- Comments

- Questions

\section{Listen:}

- Pause once in a while.

- Look for verbal and nonverbal cues.

- Ask and answer questions.

5. Summarize (end on a positive note).

\section{POSTCONFERENCE}

1. Review conference with child, if appropriate.

\section{Share information with other school} personnel, if needed.

3. Mark calendar for planned follow-up.

\section{FIGURE 3}

Conference Checklist 
knowledge, but horror stories are still cited. Parents have reported being seated on little chairs while the teacher sits in a regular-size chair. Or parents have been seated facing a light or a window. Sometimes privacy is lacking to talk over personal matters. And the teacher and parent may be separated from each other by a big table - or have no table at all to use for taking notes. Careful planning can avert these situations.

\section{Conference}

Establishing rapport in a 15-minute conference is a real challenge, but it is important. Getting up and meeting the parent at the door with a handshake will help get things off to a good start (Edge, 1993). And the teacher might relate a positive anecdote or mention something special the child did that day. The teacher should do something to break the icenot just sit there. It is said that the success of a parentteacher conference is determined in the first few minutes of the meeting.

Guidelines for the conference should be established at the onset. Parents should be informed of the time allotted for the meeting. Some research on time-limited therapies suggests that people will use the time allotted to them. The information exchange tends to be most lively as the deadline for termination approaches. If parents do not know how much time they have, they may not raise their questions or offer comments before it is time to leave. Important things can take place in a short time if the participants know what has to be accomplished and how much time they have.

The teacher should ask the parents what they think about the teacher's taking notes during the conference. Some like the idea and some don't. Sometimes, if the teacher wants to take notes and lets the parents know he or she will give them a copy of the notes at the end of the meeting, they are willing to go along with it. Or the conference can be tape-recorded, but that has its own limitations, as discussed previously.

Parents often have to be encouraged to share information. Many parents have a mindset that they are going to a meeting to hear about their child - not to give the teacher information about their child. The tip sheets in Appendix A can be a boon here.

Listening is the topic of chapter 5. It is not as easy as it may seem because, by nature or training, educators are highly verbal. We abhor silence and tend to speak up to fill the vacuum. By watching parents' body language and eye movements, we should be able to determine whether parents want to say something or are waiting for us to proceed.

The teacher is responsible for summarizing the conference, although he or she might want to ask the parents to recount the most important points to check how well they understood what was discussed. Also, the teacher may want to schedule a follow-up conference and delineate individual responsibilities.

\section{Postconference}

The child often attends the conferences along with the parents. To maximize the child's role, teachers are planning student-led conferences in which the student explains the goals and objectives of his or her program. Often, students participate in planning the goals for the next grading period.

If the student was not at the conference, the major points should be shared with him or her. The teacher often writes up the content of the conference, with an indication of what is to transpire before the next conference.

\section{DEALING WITH AGGRESSION}

Occasionally teachers get involved in a hostile or aggressive interaction (Brooks-Bonner, 1994). Success in meeting with hostile parents can result from careful planning, an understanding of human behavior, and experience. Prior to the conference, teachers should ask themselves five basic questions:

1. Do I have confidence in my ability to conduct the conference?

2. Do I know enough about the conference participants?

3. Do I clearly understand the problem?

4. Have I scheduled sufficient time for the conference?

5. Have I developed a plan of action?

Establishing some ground rules can reduce the emotional stress of dealing with angry parties. These rules include the following:

1. Focus on the issues, not the people.

2. Allow anyone to speak for a given time without interruption.

3. Dismiss a question only when everyone present agrees that further discussion is not necessary.

4. Record the important points.

5. Include all participants in the proposed solutions.

6. Ask for the parents' response at appropriate times, but do not allow interruptions.

Parents and teachers must try to reach agreement in outlining the three steps: defining the problem, analyzing the problem, and generating and selecting solutions.

A counselor was asked to conduct a parent group consisting of parents of children with behavior disorders. The parents came to the meeting hostile about a number of events that had occurred. In opening the meeting, the counselor asked for their concerns, and the parents were eager to have their say: Their children didn't like the food. They were having to ride the bus too long. There were fights on the playground.

"Wait a minute. I'm not sure I can remember all of this," the counselor said. "Let me write down what you're saying." He picked up a piece of chalk and went to the board. 


\section{Tips for Dealing With Aggressive Parents}

DO:

- Listen.

- Write down what parents say.

- When they pause, ask what else is bothering them.

- Exhaust their list of complaints.

- Ask them to clarify any specific complaints that are too general.

- Show them the list and ask whether it is accurate and complete.

- Ask for their suggestions for solving any of the problems listed.

- Write down their suggestions.

- As much as possible, mirror their behaviors, verbal and nonverbal. For example, if they speak louder, speak softer.

\section{DON'T:}

- Argue.

- Become defensive.

- Promise things you can't produce.

- Own problems that belong to others.

- Raise your voice.

- Belittle or minimize the problem.

Source: Developed by the Parent Center, Albuquerque, NM.

Immediately the parents quieted as he began to list their concerns one by one. He did not stop to discuss, argue, or defend any item as he recorded them. Then the parents clarified the concerns that seemed vague.

Going down the list, the counselor elicited suggestions for solving the problems, and the group generated a list of things to do. The counselor tried not to own any of the problems himself but left them to the parents to resolve. In essence, he taught them how to approach the solutions to their own problems. He kept his voice low and calm and didn't promise anything he couldn't produce.

When a professional comes on strong, the tendency for parents is to get defensive. By listening nonjudgmentally, the counselor or teacher gives parents an opportunity to purge their feelings. And writing down the concerns slows the tempo and assures parents that their concerns are being taken seriously.

\section{CROSS-CULTURAL CONSIDERATIONS FOR IMPROVING PARENT-TEACHER CONFERENCES}

Parents of children with special needs are particularly sensitive about discussing their families' and their children's educational needs. This anxiety may be exacerbated if cultural differences come into play.

\begin{abstract}
Teachers face the challenge of becoming aware of the personal beliefs, values, and expectations that guide their interactions with others.... If the proper groundwork is laid to create a welcoming environment for parents and students, and if appropriate interaction practices are used, educators can encourage a level of parental involvement that will benefit students academically and socially. (Jordan, ReyesBlanes, Peel, Peel, \& Lane, 1998)
\end{abstract}

They offer the following five guidelines:

1. Determine whether the conference is casual or purposeful (casual conferences are chatty, unscheduled, and informal; purposeful conferences focus on a particular topic).

2. Prepare for the conference by finding out about family roles and expectations for the child's behavior and academic performance.

3. Become culturally competent.

4. Plan the physical setting and make sure it is comfortable, private, and barrier-free.

5. Deliver information clearly, constructively, and completely so the parents will understand it. Avoid jargon, and be sensitive to the family's cultural reaction to a child's disability.

In addition, the teacher should:

6. Assess the family's cultural background. Do family members speak, read, and write English? If so, how well?

7. Make written reports simple, and explain anything verbally that the parents don't understand in writing.

8. Develop a "survival vocabulary" list in the family's native language for use with parents and school personnel.

9. To ensure understanding, ask the parents to "echo" what you have communicated to them.

10. Welcome parents warmly into the school and the classroom.

11. Let the parents know their rights and responsibilities regarding their children's education.

12. Provide parents with sufficient information about the referral process, legal matters, and financial issues. (adapted from Al-Hassan \& Gardner, 2002)

\section{SUMMARY}

Early individual meetings with parents prevent or reduce potential problems of attendance, discipline, and dropout, have been shown to improve grades, and foster better homeschool contacts. Proper preparation for an initial conference 
requires research on the part of teachers into the information available. A study of the student's cumulative records may help in the teacher's developing an agenda and may raise questions for the teacher to explore with the parents.

The first aim of the initial interview is to establish rapport with the parents. Then the teacher should proceed with the prepared agenda, with a willingness to be flexible. Regularly scheduled conferences require preparation in the same way that the initial conference does. Most school districts place time restrictions on conferences, so to get the most out of the limited time for meetings, teachers might send home in advance some suggestions and tips on things parents can do to prepare for the meeting.

At the conference, the teacher should have on hand all materials needed for the meeting. Teachers should take enough time to listen to the parents and encourage them to bring up questions and comments. After the conference, the teacher should pass along the major points to the child (if the child was not present) and to other school personnel, if needed.

Occasionally a teacher faces a hostile parent. Some responses to aggression include keeping cool, listening, writing down what the other person says, eliciting suggestions to resolve the concerns, not promising things they can't produce, not owning other people's problems, and not becoming defensive. An old adage is, "If you argue with a fool, it makes two fools."

\section{REFERENCES}

Al-Hassan, S., \& Gardner, R. (2002). Involving immigrant parents of students with disabilities in the educational process. Teaching Exceptional Children, 34(5), 52-58.

Benard, B. (1991). Fostering resiliency in kids: Protective factors in the family, school, and community. Portland, OR: Western Center for Drug-Free Schools and Communities. (ERIC Document Reproduction Service No. ED 335 781).

Brooks-Bonner, L., (1994). When parents get aggressive. Education Digest, 59(6), 33.

Edge, D. (1993). Techniques for conducting a parent conference [videotape]. Louisville, KY: University of Louisville.

Edge, D. (1995a). Conducting parent-teacher conferences [videotape]. Louisville, KY: University of Louisville.

Edge D. (1995b). Preparing for parent-teacher conferences [videotape]. Louisville, KY: University of Louisville.

Jordan, L., Reyes-Blanes, M., Peel, B. B., Peel, H. A., \& Lane, H. B. (1998). Developing teacher-parent partnerships across cultures: Effective parent conferences. Intervention in School and Clinic, 33(3), 141-147.

Maring, G.H., \& Magelky, J., (1990). Effective communication: Key to parent/community involvement. Reading Teacher, 43(8), 606-607.

\section{INDEX ・ Volume 39}

Author Index

Arguello, JoAnna L. (November 2006)

Bell, G. Ronald (January 2007)

Blando, John A. (October 2006)

Blasik, Jessica (January 2007)

Camik, Leigh Ann (January 2007)

Chen-Hayes, Stuart F. (February 2007)

Consoli, Andrés J. (December 2006)

Crothers, Laura M. (January 2007)

Edge, Denzil (May 2007)

Field, Julaine E. (January 2007)

Grazioso, María del Pilar (December 2006)

Greisler, Michael J. (January 2007)

Keener, Dana (January 2007)

Kolbert, Jered B. (January 2007)

Kroth, Roger L. (May 2007)

Liu, William Ming (November 2006)

López, Marisela (December 2006)

Olkin, Rhoda (April 2007)

Orozco, Graciela León (March 2007)

Salazar, Carmen F. (September 2006)
Chronological Index of Titles

Conceptualizing Multiple Identities and Multiple Oppressions in Clients' Lives (September 2006)

Spirituality, Religion, and Counseling (October 2006)

Using Social Class and Classism in Counseling (November 2006)

Building International Relations: Advancing Counseling and Fostering Human Development (December 2006)

Relational Aggression in Childhood and Adolescence: Etiology, Characteristics, Diagnostic Assessment, and Treatment (January 2007)

The ACCESS Questionnaire: Assessing School Counseling Programs and Interventions to Ensure Equity and Success for Every Student (February 2007)

Reaching Out to Immigrant Students and Families: A Task for Counselors in the Schools (March 2007)

Disability-Affirmative Therapy and Case Formulation: A Template for Understanding Disability in a Clinical Context (April 2007)

Assistive Technology and Devices (May 2007) 